\title{
ALCIDES MAYA, CRÍTICO DE MACHADO: O HUMOUR COMO DIFERENÇA
}

\author{
Léa Masina
}

\begin{abstract}
Resumo: The essays by Alcides Maya show the changements the 19th century literary criticism in Rio Grande do Sul have undergone. In this respect, the essay "Machado de assis: algumas notas sobre o humour" (1912) makes the reading of the passage from the naturalistic literary criticism to another based on the questions of erudition and cosmopolitism, antecipating the very issues of contemporary comparative approaches as in literature. The comparative approach to the study of the humour also contributed to revitalize the paradigms of the Brazilian literary criticism at the end do the 19th century, by rejecting the reducing aspects of nationalism and following the path initated by Machado de Assis himself in "Notícia de Literatura Brasileira: Instituto de Nacionalidade" (1873).
\end{abstract}

Palavras-chave: literatura comparada, crítica literária, literatura sul-riograndense, Alcides Maia, humour, Machado de Assis.

Crítico literário e ficcionista, Alcides Maya desfrutou de grande prestígio nos meios intelectuais do Brasil entre fins de XIX e as duas primeiras décadas do século XX. Dotado de erudição e militando desde cedo no jornalismo, foi o primeiro intelectual a exercer sistematicamente a crítica no Rio Grande do Sul, cujas fronteiras culturais ultrapassou , vindo a ocupar a cadeira que fôra de Aluízio Azevedo na Academia Brasileira de Letras.

A obra ficcional do escritor compõe-se do romance social Ruínas Vivas (1910) e de dois livros de contos, Tapera (1911) e Alma Bárbara (1922). O tom nostálgico e a temática regionalista das narrativas, considerados reacionários a partir do Modernismo de 22, somando-se a dificuldades de ordem particular, foram os responsáveis pelo desinteresse na reedição de sua obra. Sua ficção e seus ensaios constituem vertente importante para a crítica comparatista, porque paradigmáticos do tipo de relação que o intelectual brasileiro estabeleceu com os centros cultos da Europa e do Brasil, no processo de assimilação cultural e literária.

Em confronto com os ensaios anteriores, Machado de assis: algumas notas sobre o humour permite examinar a mudança de uma concepção naturalista da crítica, para outra capaz de apreender a singularidade da obra, à revelia de modelos. O cotejo desse ensaio com a tradição crítica brasileira naturalista permite ver de que modo o escritor apreende o humour machadiano como elemento de diferença.

Machado de Assis: algumas notas sobre o humour é publicado quinze anos após o estudo de Silvio Romero sobre a obra de Machado. As polêmicas registradas quando da publicação do texto romeriano, em 1897, depõem sobre a importância do romancista no mundo literário da época. Informam também sobre os diferentes procedimentos da crítica que, ou seguia o modelo naturalista, positivista e tainiano, "não estético", de Silvio Romero, ou optava por abordagens "técnicas" ou pelos modelos estéticos, conforme o faziam Araripe Júnior e José Veríssimo, de quem a obra machadian também fora objeto de interesse.

A polêmica inicia-se, pois, em 1897, ano em que, no Rio Grande do Sul, Alcides Maya lança Pelo Futuro, seu primeiro primeiro livro de ensaios. Envolvendo um número expressivo de críticos, as discussões sobre a obra de Machado ocupam o centro do país até o ano de 1909, quando Romero publica Zeverissimações ineptas da crítica. Mais do que divergências teórico-críticas, caracteriza a polêmica o personalismo dos debates que, com o correr do tempo, tomaram outros rumos, marcando posições opostas com relação à crítica e à literatura brasileira.

Maya, ao ler Machado, lê Romero e contra ele se posiciona com segurança e independência crítica. Para operacionalizar essa mudança, serve-se do raciocínio comparatista e apreende o humour 
como traço de diferença, integrando Machado à família dos grandes humouristas universais. Dá-se conta também do caráter redutor da crítica tainiana, cujos vetores são insuficientes para valorar a qualidade estética da obra literária. Rejeita, desse modo, o critério nacionalista, eleito por Silvio Romero como indispensável para qualificar as obras escritas no Brasil. Ao fazê-lo, alinha-se ao próprio Machado, cujas idéias sobre a Literatura Brasileira - Instinto de Nacionalidade (1873) fornecem-lhe epígrafes aos capítulos finais de seu ensaio. O texto machadiano, que influirá no reordenamento conceitual da crítica e especificamente na compreensão do nacionalismo no Brasil, por sua vez, retoma a vertente da crítica romântica, formando os elos de uma tradição. Ao discutir o nacionalismo como fundamento de doutrina e ao romper com o antagonismo entre nacional e universal, Machado inicia uma reflexão cujo ápice irá ocorrer no Modernismo, através da obra de Mário de Andrade. Como observa Tania Franco Carvalhal,

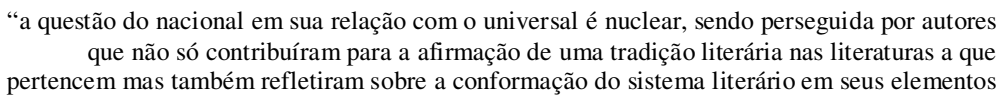
que não só contribuíram para a afirmação de uma tradição literária nas literaturas a que pertencem mas também refletiram sobre a conformação do sistema literário em seus elementos essenciais".

O ensaio sobre o humour de Machado coloca algumas questões teóricas de modo inovador. Primeiro, considera que este não constitui critério de escola, nem é gênero literário, mas oposição ao gênero; isso porque, nele, a consciência do escritor sobrepõe-se à norma. Reconhce também e de modo pioneiro, a independência de Machado sobre escolas e modismos literários. Em seguida, ao aproximar humoristas de diferentes nacionalidades, desenvolve a noção de "famílias literárias", apontando afinidades estilísticas e psicológicas. Essa noção de ser lida hoje como indicativo de supranacionalidade, pois dela decorre a compreensão do caráter universal do humour. Seria esse o elemento de distinção, restrito a alguns escritores psicologicamente dotados de determinadas condições individuais. Essa tendência original determinaria a percepção do mundo, permitindo ao crítico agrupar autores distintono tempo e no espaço, como Rabelais, Sterne, Molière e Cervantes.

Não obstante, fortemente marcado pelo evolucionismo spenceriano, Maya não descura o caráter sociológico da crítica que realiza. Para o crítico os humoristas partilham um momento análogo de transição cultural, responsável pelo surgimento de uma crise de valores. Daí a concluir que a dúvida, juntamente com o pessimismo e a amargura, será um elemento importante na constituição do humour machadiano.

No tocante à metodologia da crítica naturalista, desenvolvida no Brasil a partir da geração crítica de 1870, a apreensão do humour como característica psicologia representa um desvio em meio à afirmação da nacionalidade pelo reconhecimento dos fatores de Taine (raça, meio e momento). Nesse sentido, o humour como traço psicológico representa a leitura da diferença.

O modelo crítico de Taine e o evolucionismo de Spencer, de que Maya fora um dos principais divulgadores no Rio Grande do Sul, postos a serviço do nacionalismo, da visão de mundo otimista e da crença no progresso, pareciam-lhe insuficientes para dar conta do literário. A crítica na História de Literatura Brasileira, deixam flagrantes os paradoxos da crítica naturalista que, ao pretender-se científica e apta a apreender o sentimento coletivo do povo e da sociedade, criava espaço para o subjetivismo e a idiossincrasia.

Quinze anos após a polêmica que deu inícios ao "caso Machado de Assis", o ensaio de Alcides Maya propôs uma dupla leitura: da obra de Machado sob a égide do humour e sob o influxo do humourismo setecentista de Sterne; e da obra crítica de Romero, sobretudo do nacionalismo literário considerado como vetor para aquilatar a qualidade literária dos seus contemporâneos.

Lido hoje, à distância de quase um século, o texto registra o percurso de um intelectual que abandona os modelos científicos e naturalistas em buscas de maior acuidade crítica. Recolhe, nesse trajeto a que situa o Rio Grande no centro dos debates culturais do país.

No primeiro capítulo do ensaio, Maya define o humour como

$$
\begin{array}{r}
\text { "enfado e tristeza do mundo e do homem, mas tristeza mista de impassibilidade e de pena à } \\
\text { percepção das coisas e enfado que o prazer da análise tempera de orgulho". Sendo traço } \\
\text { psicológico, sequer, um gênero, de regras fixas: é antes oposição aos gêneros a consciência do } \\
\text { escritor sobreposta à norma" (...) }
\end{array}
$$

No cotejo dessa leitura com outras da mesma época, percebe-se o quanto essa antecipa a Literatura Comparada, mesmo quando aponta o traço psicológico como elemento de aproximação entre diferentes obras e autores. Não obstante, permanecem algumas questões: de que modo o comparatismo tradicional, restrito a análise conteudística da literatura (temas, fontes e influências), contribuiu para a formação do discurso crítico brasileiro; até onde o discurso erudito, legitimado no seio de uma sociedade dependente e monoculturalista, é representativo da tensão do intelectual brasileiro de novecentos. E a que 
serviram essas raras contribuições individuais ante ao predomínio de uma crítica redutora e homogeneizante.

Mesmo na certeza de que as indagações tendem a multiplicar-se no confronto com outras literaturas, sobretudo as da América Latina, irmanadas por processos paralelos de colonização; e mesmo levando em conta a impossibilidade e a inoperância de buscar respostas de natureza totalizante retornemos à obra de Alcides Maya. Há nela um projeto que integra, a seu modo, o programa nacionalista literário brasileiro, no qual o fazer crítico representa um papel preponderante. A inquietação intelectual do autor, cujo pensamento se desloca do Brasil para a Europa e do sul para o centro, direciona-o também para a prática jornalística.

Nesse sentido, a militância em periódicos por mais de uma década, atuando como crítico literário, permitiram que lesse em Machado não apenas a cópia dos inglêses, como dizia Silvio Romero. A competência de leitor de muitos textos permite-lhe perceber a proximidade entre autores, pela identificação psicológica e estilística dos humouristas, independente da cronologia, de fontes e de influências. No diálogo intertextual, o Machado de Maya cria e atualiza seus antecessores.

Por outro lado,

"a própria formação cultural do país, dirigida para a adaptação do modelo europeu de que era
caudatário, forçava, por um lado, a tradução de temas e técnicas e, por outro, obrigava a
vinculação da atividade cultural ao sentido histórico de identificação da nacionalidade".

Se o paradigma crítico era dado pelo ângulo da interpretação, como sugere João Alexandre Barbosa, e se a crítica naturalista pretendera "interpretar os produtos culturais em função de uma ideia geral do país", no caso, o nacionalismo, o estudo de Maya constitui um avanço crítico. A mudança de percurso, substituindo o critério da representatividade nacional para a individuação do escritor e sua identificação psicológica com a "família ocidental" dos humouristas, assegura o predomínio da vertente interpretativa conjugada à analítica. Desse modo, além de ilustrar a passagem à crítica invervalar que se produz no Brasil nos primórdios do século XX, seu texto passa a integrar, inovando, a fortuna crítica machadiana. Tanto assim que suas afirmações tem sido retomadas pela crítica: dentre elas, o caráter psicológico do humour, expresso num modo peculiar de linguagem; a independência intelectual de Machado; a diferença de sua obra no conjunto epocal de escolas ou períodos, enquanto representação ao mesmo tempo particularizada e universal.

Por outro lado, é preciso registrar o interesse de Alcides Maya pela questão da supranacionalidade cultural. Num texto intitulado À sombra de Rénan, em Crônicas e ensaios (1918), ele observa que

\footnotetext{
“ Kant, Goete Fichte, Beethoven não são talentos germânicos e, sim, genios humanos. Demoram, por isso, acima do Rheno e da Floresta Negra; prendem-se à Grécia, à Roma, à França, ao movimento geral das idéias e dos sentimentos do nosso ciclo".
}

A erudição do autor e os conhecimentos de história literária permitem-lhe exercitar um comparatismo avant la lettre, criando espaços para observações de natureza induitiva. O ensaio Machado de Assis aponta o jogo de contrastes, a indiferença pelo público, o imprevisto da imaginação poética, o desrespeito aos cânones, que caracterizaria a família dos humouristas, assegurando-lhe identidade para além das fronteiras nacionais. Referindo a obra de Sterne, Swift, Rabelais, Molière e Cervantes, o crítico argumenta que

\footnotetext{
“A prova temo-la na existência de grandes humoristas fora das fronteiras germânicas (...) temolo ainda na identidade de filosofia observável na obra dos grandes humoristas, quaisquer que sejam os respectivos países; e, finalmente, no fato de serem comuns a todos eles os caracteres apontados por Taine, e já antes dele bem definido."
}

As semelhanças entre humouristas ocorreria, portanto, por conta de transformações sociais captadas e vividas de modo semelhante. As coincidências temporais que consideram o humor como fenômeno psicológico, "identidade da natureza humana, sujeita às mesmas leis, reguladores de uma evolução comum” (MA:26) levam Maya a indagar:

"Porque há de a crítica limitar um fenômeno literário tão geral e tão humano a uma certa raça, produto de habitat determinado?"

Nesse sentido, percebendo, pela aproximação comparatista, a originalidade e os usos individual, concluise que:

“(...) entre o estilo titânico de Dante e o estro despeiado e cavalheiresco, ardente e lírico de Camões; entre a severidade majestosa e apaixonada de Calderon e a profundez sombria, sulcada de relâmpagos, de Shakeaspeare; entre a sintaxe de Cervantes e a de Rabelais, há 
dissemelhanças como há afinidades entre escritores e poetas de um mesmo país. Na estridência da vozearia dos velhos northmen na sua fúria de vida - quem não verá, apesar do acento próprio, um elemento comum com Shakespeare e com Byron?'(26)

A alusão à sintaxe de Cervantes e Rabelais abrangeria uma incursão do crítico à forma, no que estaria próximo a Araripe Júnior pela preocupação com os modos de narrar. Embora a perspectiva naturalista e evolucionista, por detrás da suposta base científica, tenha servido para encobrir um subjetivismo crítico e impressionista, o ensaio sobre humour machadiano surge dentro e contra o espaço discursivo novecentista. Se o humour é universalidade, é também a dúvida:

“(...) é Satã predominando, é o acento de revolta no gargalhar estridente, simbolicamente pungitivo de Mephisto, o divino rebelde, o supremo melancóli 